\title{
EFEITO DO EXTRATO DE OXICOCO NO TRATAMENTO DE INFECÇÕES DO TRATO URINÁRIO EM PORCAS
}

\author{
Kelly Mazutti ${ }^{1}$, Geraldo Camilo Alberton ${ }^{1}$, Fabiano Montiani Ferreira ${ }^{1}$, Isabella \\ Lunardon', Everson Zotti², Saulo Weber ${ }^{3}$ \\ 1 UFPR \\ 2 PUC-PR Campus Toledo \\ 3 PUC-PR Campus São José dos Pinhais \\ Correspondência: Kelly Mazutti: kellymazutti@hotmail.com
}

\begin{abstract}
RESUMO: O experimento consistiu na avaliação da eficácia de um produto comercial a base de extrato de oxicoco (pHD® - Biomin LTDA) no tratamento de infecções do trato urinário (ITU) em porcas. Foram utilizadas 42 porcas, com idade gestacional variando entre 50 e 70 dias, portadoras ou não de ITU. Os animais sadios foram diferenciados dos animais afetados mediante resultados de urinálise e urocultivo. $\mathrm{O}$ ensaio foi composto por: porcas com ITU que receberam o produto a base de extrato de oxicoco na ração por um período de 14 dias; porcas negativas para ITU (controle negativo); e porcas positivas para ITU (controle positivo). Foram coletadas amostras de urina nos dias zero, sete e 14 após o início do tratamento. Realizou-se urinálise completa dessas amostras, avaliação da densidade urinária específica, do $\mathrm{pH}$, contagem bacteriana e isolamento bacteriano. A $E$. coli foi o agente mais frequente no isolamento bacteriano $(90,62 \%)$. Os resultados demonstraram que o produto a base de extrato de oxicoco foi eficaz em promover redução do $\mathrm{pH}$ urinário, porém não interferiu em mais nenhum dos outros parâmetros avaliados.
\end{abstract}

Palavras-chave: acidificante urinário; contagem bacteriana; Escherichia coli; pH; urinálise

\section{EFFECTS OF CRANBERRY EXTRACT IN THE TREATMENT OF URINARY TRACT INFECTIONS IN SOWS}

\begin{abstract}
The experiment consisted in assessing the effectiveness of a commercial product based on cranberry extracts ( $\mathrm{pHD}{ }^{8}$ - Biomin LTDA) in the treatment of urinary tract infections (UTI) in sows. Were used 42 sows, with gestational ages ranging between 50 and 70 days, either suffering from UTI or not. Healthy animals were differentiated from affected animals by urinalysis and urine culture. The experiment was composed of sows with UTI that received the cranberry extract product in the diet for a period of 14 days; sows negative for UTI (negative controls) and sows positive for UTI (positive controls). The former two groups did not receive the cranberry extract product in the diet. Urine samples were collected on days zero, seven and 14 after initiation of treatment. Complete urinalysis of these samples, urine specific gravity, $\mathrm{pH}$, bacterial count and bacterial isolation were performed. E. coli was the most frequent isolated agent $(90,62 \%)$. The results showed that the commercial product made with cranberry extract was effective in promoting a reduction of urinary $\mathrm{pH}$, but did not interfere in any other parameters observed.
\end{abstract}

Key Words: bacterial count; Escherichia coli; pH; urinalysis; urinary acidifiers 


\section{INTRODUÇÃO}

Nos atuais sistemas de criação intensiva de suínos a prevalência de infecções do trato urinário (ITU) em porcas pode variar de 10 a $64 \%$ (Sanz et al., 2007; Sobestiansky et al., 2007), provocando perdas econômicas consideráveis, principalmente devido às falhas reprodutivas, mortes súbitas e redução da vida útil das matrizes.

Os microorganismos envolvidos com maior frequência nas ITU em porcas são Escherichia coli, Proteus mirabilis, Staphylococcus sp., Streptococcus sp., Aeromonas hydrophila e Actinobaculum suis (Sobestiansky et al., 2007). Similarmente, em mulheres, a E. coli uropatogênica (UPEC) é o agente etiológico mais comum, entretanto, existem muitos outros uropatógenos significativos, incluindo Staphylococcus saprophyticus, Klebsiella pneumoniae, e Proteus mirabilis (Rosen et al., 2008).

O controle das ITU no rebanho suíno depende da adoção de várias medidas de prevenção e tratamento. $O$ tratamento geralmente envolve antibioticoterapia individual ou coletiva via ração por um período de 10 a 14 dias (Dalla costa e Sobestiansky, 1999; Sobestiansky et al., 2007). O uso de acidificantes da urina como os ácidos orgânicos, cloreto de amônio, vitamina C e o ácido cítrico também tem sido adotados como medida de controle (Dee et al., 1994; Meister, 2006; Oliveira, 2010).

Os acidificantes da urina não possuem efeito terapêutico na ITU, mas são recomendados para inibir o crescimento de bactérias patogênicas, além de estimularem maior consumo de água (Koller et al.,2006). Estudo realizado por Mroz (2005) demonstrou que 0 ácido benzóico aumenta a digestibilidade de aminoácidos e nitrogênio, aumenta a acidez urinária e reduz a emissão de amônia pelos dejetos. Além disso, a principal via de excreção do ácido benzóico é a urinária (em até 24 horas), onde é eliminado $48 \%$ da dose na forma de ácido hipúrico (86\% do total) (Bridges et al., 1970), promovendo a diminuição da proliferação bacteriana na bexiga por efeito bacteriostático. Uma das fontes de ácido benzóico encontrada na natureza é a fruta Vaccinium Macrocarpon Aiton (Raz et al., 2004), conhecida no Brasil como oxicoco ou uva-do-monte (Fonte, 2008).

Estudos em seres humanos demonstraram que o oxicoco é capaz de impedir a aderência da Escherichia coli nas células epiteliais superficiais da bexiga, contribuindo assim para a manutenção da saúde do trato urinário (Sobota, 1984; Schmidt e Sobota, 1988; Zafriri et al., 1989; HOWELL et al., 2005). Avorn et al. (1994) demonstraram que o suco de oxicoco reduziu a frequência de bacteriúria com piúria em mulheres idosas e Česonienè et al.(2009) verificaram que o uso de extratos dessa fruta inibe o crescimento de grande variedade de bactérias patogênicas humanas, tanto Gramnegativas (Escherichia coli e Salmonella typhimurium) quanto Gram-positivas (Enterococcus faecalis, Listeria monocytogenes, Staphylococcus aureus e Bacillus subtilis). Entre os seus componentes estão os flavonóides, antocianinas, catequinas, triterpenos, ácidos orgânicos, e uma pequena quantidade de ácido ascórbico. Os principais ácidos orgânicos são: cítrico, málico e ácidos quínico, com pequenas quantidades de ácido benzóico e glucurônico (Borukh et al., 1972).

O objetivo deste estudo foi testar a capacidade acidificante e antimicrobiana de um produto comercial a base de extrato de oxicoco, pHD® Biomin LTDA, no tratamento da infecção do trato urinário em porcas. 


\section{MATERIAL E MÉTODOS}

O experimento foi realizado em granja de reprodutores suídeos certificada (GRSC). Utilizaram-se 42 porcas gestantes de linhagens comerciais, alojadas em gaiolas individuais e com acesso a bebedouro tipo calha. A quantidade e o tipo de ração consumida pelos animais durante o período do experimento seguiu o padrão de rotina já estabelecido pela granja de acordo com a idade gestacional das porcas, e formuladas de acordo com as recomendações do NRC (1998) para matrizes gestantes. Os animais receberam água à vontade durante todo o período.

Os animais foram dispostos em três grupos da seguinte forma: Grupo tratado - 22 porcas com ITU que receberam ração da própria granja, adicionada de $\mathrm{pHD} \AA$, durante 14 dias, na dose de 20g/porca/dia (recomendação do fabricante). As doses de $\mathrm{pHD} \AA$ eram pesadas diariamente e misturadas em $400 \mathrm{~g}$ de ração umidificada. A ração era molhada para evitar que o conteúdo se espalhasse e a porca da gaiola ao lado tivesse acesso. A mistura era colocada no piso em frente à porca; Controle negativo - 10 porcas sem ITU que receberam ração da própria granja, sem qualquer suplementação; Controle positivo - 10 animais com ITU que receberam ração da própria granja, sem qualquer suplementação.

Para a seleção das fêmeas que compuseram os grupos experimentais foi realizada urinálise (exame físico e químico com tiras reativas) de 253 porcas, das quais se selecionaram 32 que apresentaram positividade para 0 nitrito (ITU positivas) para comporem os grupos tratado e controle positivo, e 10 sem nitrituria (ITU negativas) e com urinas incolor, límpidas e inodoras, para comporem o grupo controle negativo.
Durante o experimento, as porcas foram submetidas a coletas de urina nos dias zero, sete e 14 após o início do tratamento. As amostras de urina foram colhidas no período da manhã, antes do amanhecer e do primeiro arraçoamento, em frascos estéreis. Aguardava-se a micção espontânea e coletava-se a urina do jato médio, desprezando-se o primeiro jato. As porcas que não urinavam na primeira hora da colheita eram expostas a um cachaço sexualmente maduro para estimular a micção. Após a coleta, os frascos eram fechados e colocados atrás da gaiola das respectivas porcas. Terminada a coleta, os frascos eram secados com papel toalha e numerados de acordo com o brinco das porcas. As amostras foram acondicionadas em caixas isotérmicas com gelo e conduzidas ao laboratório da granja para a realização imediata do exame físico, químico e microscópico destas urinas.

A avaliação da urina foi realizada conforme metodologia descrita por Strasinger et al. (1998). No exame físico foi avaliado a coloração (incolor, amarelo-clara, amarelo, amareloescura), a aparência (normal ou turva), e o odor (normal, amoniacal ou pútrido) das amostras de urina. O exame químico foi realizado com tiras reativas (Uriquest $\left.{ }^{\circledR}\right)^{1}$. Os parâmetros avaliados foram: nitrito sangue e proteína. A densidade urinária específica foi obtida por refratometria. $\mathrm{O}$ exame microscópico da urina (sedimentoscopia) foi realizado em microscópio óptico comum na objetiva $40 \mathrm{x}$. As hemácias, células epiteliais e leucócitos foram quantificados como número por média de dez campos. As bactérias e os cristais foram classificados conforme critérios visuais e subjetivos, sendo registrados como ausente $(-)$, raros $(R)$, discreto $(+)$,

\footnotetext{
${ }^{1}$ Uriquest ${ }^{\circledR}$ : Labtest Diagnóstica S. A. - Brasil
} 
moderado $(++)$, acentuado ou incontável $(+++)$.

Para as contagens bacterianas, isolamento bacteriológico e mensuração do $\mathrm{pH}$ em peagâmetro, as amostras de urina acondicionadas em caixas isotérmicas com gelo foram enviadas para o Centro de Diagnóstico de Sanidade Animal - CEDISA. O tempo entre a coleta e o início do processamento no CEDISA foi de 23 horas em média.

As amostras foram semeadas em agar sangue ovino 5\%, Mac Conkey e em Tryptic Soy Agar (TSA) para contagem de colônias. Amostras que apresentaram contagem igual ou superior a $10^{5}$ UFC/mL foram consideradas positivas para infecção urinária (Fairbrother, 2006). As bactérias foram identificadas mediante Gram e provas bioquímicas (SIM, TSI, CIT, O/F, VM, Catalase). As bactérias identificadas como Cocobacilos Gram negativos foram submetidas a provas bioquímicas complementares (ONPG, ADH, LDC, ODC, CIT, $\mathrm{H}_{2} \mathrm{~S}$, URE, TDA, IND, VP, GEL, GLU, MAN, INO, SOR, RHA, SAC, MEL, AMY, ARA, OX) com o uso do kit comercial Api 20 E (BioMérieux®) ${ }^{2}$.

Os dados obtidos cujas variáveis eram contínuas numéricas de distribuição normal foram submetidos ao teste ANOVA empregando o pós-teste de Tukey, considerando diferenças estatísticas quando 0 valor de $P \leq 0,05$. As variáveis contínuas numéricas que não seguiam uma distribuição normal foram transformadas em Log10 previamente à análise. As variáveis categóricas ordinais foram analisadas pelo Teste Exato de Fisher. Para avaliar as diferenças existentes entre os animais positivos e negativos para ITU foi considerada apenas a coleta do dia zero, e para estabelecer o percentual de

\footnotetext{
${ }^{2}$ BioMérieux®: Marcy l'Etoile - France
}

cristais presentes na urina foi realizada uma média entre as três coletas.

\section{RESULTADOS}

Os resultados obtidos na análise do $\mathrm{pH}$ urinário entre os diferentes grupos e dias de coleta podem ser observados na tabela 1.

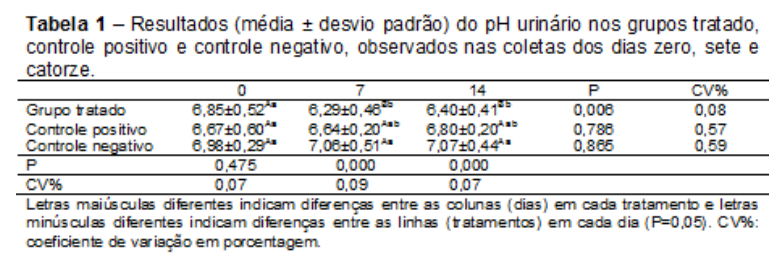

Não foi observada diferença entre - $\mathrm{pH}$ dos grupos tratado, controle positivo e negativo no dia 0 , indicando homogeneidade dos animais no início do experimento. Os grupos controle positivo e negativo não tiveram variação significativa no $\mathrm{pH}$ nas três coletas. Já no grupo tratado foi observada uma redução do $\mathrm{pH}$ após o início do tratamento, mostrando a eficiência do produto para esse fim. Observou-se também uma tendência de aumento da acidez do grupo tratado em relação ao controle positivo no decorrer do tratamento, embora não estatisticamente significativa, devido à variabilidade inerente ao material experimental.

Os resultados da densidade urinária específica podem ser observados na tabela 2.

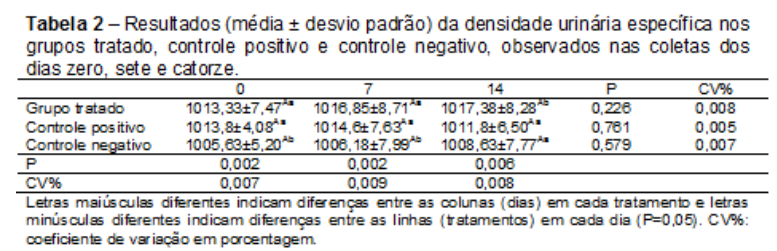

Conforme esperado, a densidade urinária específica foi significativamente superior nos grupos tratado e controle positivo, do que no grupo controle negativo. $O$ produto utilizado não 
interferiu na densidade urinária específica do grupo tratado.

Os resultados da contagem bacteriana $(\log 10)$ encontram-se na tabela 3.

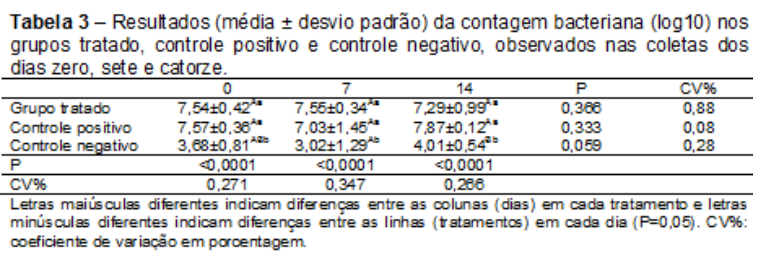

Não houve redução da contagem bacteriana no grupo tratado, o que demonstra que o produto não foi eficaz no tratamento de ITU.

No exame microscópico da urina, o número de leucócitos e bactérias por campo foi superior nos grupos controle positivo e grupo tratado do que no grupo controle, em todas as coletas, conforme já era esperado. Os demais parâmetros observados não apresentaram diferença significativa (hemáceas, leucócitos, células epiteliais e cristais). Não foi observada ação do produto utilizado no grupo tratado em nenhum dos parâmetros avaliados por sedimentoscopia.

$\mathrm{Na}$ avaliação do número de bactérias presentes por campo observou-se que as porcas com ITU que apresentaram na coleta do dia zero, independentemente de pertencerem ao grupo tratado ou controle positivo, +++, ,,$+++ \mathrm{R}$ e - foram, respectivamente, $68,75 \%, 25 \%, 6,25 \%, 0 \%$ e $0 \%$. Nos animais do grupo controle negativo foram $0 \%, \quad 0 \%, \quad 0 \%, \quad 30 \%$ e $70 \%$ respectivamente. A variação da contagem bacteriana entre as diferentes coletas, em percentual, obtida por sedimentoscopia pode ser observada na tabela 4. Os valores médios de células epiteliais por campo na coleta do dia zero foram de 0,13 para o grupo tratado, 0,08 para o controle positivo e 0,064 para o controle negativo, não havendo diferença significativa. Não foi observada a presença de eritrócitos em nenhuma das amostras na coleta do dia zero. Não houve diferença significativa $(P=0,10)$ entre os animais positivos e negativos para ITU quanto à presença de cristalúria. Do total de amostras de urina avaliadas, $38 \%$ apresentaram cristais, sendo os mais comumente observados estruvita $(14,58 \%)$, oxalato $(10,41 \%)$ e fosfato amorfo $(75 \%)$.

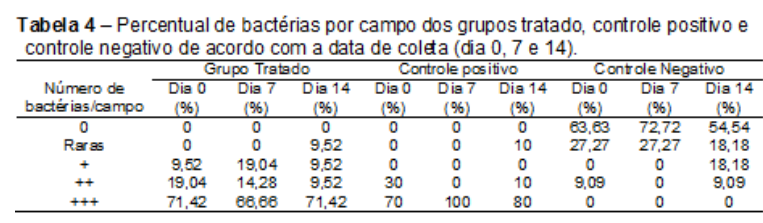

O resultado das provas bioquímicas demonstrou que a $E$. coli foi 0 agente mais frequentemente isolado (Tabela 5).

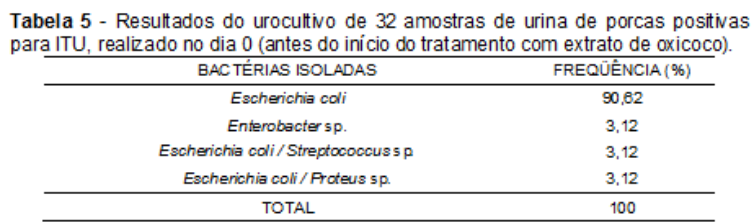

\section{DISCUSSÃO}

$\mathrm{Na}$ avaliação entre as diferentes coletas (zero, sete e 14) do grupo controle negativo houve diferença significativa apenas na contagem bacteriana $(\log 10)$ entre as coletas. Essa variação talvez possa ser explicada pelo fato de que durante 0 experimento duas porcas feriram a vulva nas gaiolas, apresentando lesões purulentas e, consequentemente, com contaminação bacteriana. Mesmo tendo sido negativas para nitrito na tira reativa, as contagens bacterianas foram elevadas $\left(>10^{4}\right)$ nestes animais.

No grupo tratado, dentre todos os parâmetros avaliados, observou-se ação do produto apenas sobre $\mathrm{opH}$ urinário. Percebe-se que houve redução significativa do $\mathrm{pH}$ urinário tanto na coleta do dia sete como na coleta do dia 14. A redução do $\mathrm{pH}$ urinário é um dos mecanismos naturais de defesa contra a 
proliferação bacteriana na bexiga (Jones, 2003). Não existem estudos em porcas demonstrando a capacidade do oxicoco em acidificar a urina. Todos os estudos encontrados foram realizados em seres humanos. Porém, acredita-se que o mecanismo pelo qual o oxicoco foi capaz de promover redução significativa do $\mathrm{pH}$ urinário das porcas do grupo tratado seja o mesmo demonstrado em seres humanos. A acidificação da urina após a ingestão de oxicoco já foi relatada em 1914 por Blatherwick, que demonstrou que a fruta é rica em ácido benzóico, o qual é excretado pela urina na forma de ácido hipúrico, e funcionaria como um agente bacteriostático. Ao longo dos anos diversos estudos demonstram a capacidade do oxicoco de acidificar a urina (Blatherwick et al., 1923; Fellers et al., 1933; Moen, 1962; Kahn et al., 1967; Der Marderosian, 1977; Kinney et al., 1979; Schultz, 1984; Jackson et al., 1997). Em contraste, a baixa quantidade de ácido benzóico presente na fruta $(<0,1 \%$ do peso), juntamente com os montantes máximos de suco de oxicoco tolerados, devido à acidez da fruta, raramente resulta em excreção suficiente de ácido hipúrico necessária para atingir concentrações urinárias bacteriostáticas (Bodel et al., 1959; Zinsser, 1964; Kahn et al., 1967; Mcleod et al., 1978; Avorn et al., 1994; Linsenmeyer et al., 2004; Waites et al., 2004).

As contagens bacterianas não sofreram qualquer interferência da suplementação com extrato de oxicoco, o que demonstra que o produto não foi eficaz no tratamento da ITU em porcas. Esses achados corroboram com diversos estudos em seres humanos que também relatam não terem observado redução na contagem bacteriana após o tratamento com oxicoco (Haverkorn e Mandigers,1994; Schlager et al., 1999; Linsenmeyer et al., 2004; Waites et al., 2004). Entretanto, Reid et al. (2001), verificaram em 15 pacientes com lesão medular, que o oxicoco reduziu a carga bacteriana do biofilme na bexiga.

Da mesma forma como ocorreu neste estudo, não existem evidências em seres humanos, até o momento, que sugiram que o suco de oxicoco ou os produtos a base de oxicoco sejam efetivos para o tratamento da ITU. Todos os estudos encontrados apontam - oxicoco como sendo efetivo na redução da incidência de ITU, atuando assim de forma preventiva (Zafriri et al., 1989; Ofek et al., 1991; Haverkorn e Mandigers, 1994; Dignam et al., 1997; Lowe et al., 2001; Howell et al., 2002). Essa fruta demonstrou ser eficiente na prevenção da ITU mesmo em mulheres que sofrem de ITU recorrente (Walker et al., 1997; Kontiokari et al., 2001; Stothers 2002; Kiel e Nashelsky, 2003). Em contraste, outros estudos não mostraram nenhum benefício do oxicoco para a prevenção da ITU (Schlager et al., 1999; Kirchhoff et al., 2001). A explicação pela qual o oxicoco é capaz de prevenir a ITU, além de promover acidificação da urina, está relacionada à sua capacidade de inibir a aderência das fímbrias da Escherichia coli nas células uroepiteliais (Sobota, 1984; Zafriri et al., 1989; Ofek et al., 1991), que é o passo inicial na patogênese da ITU (Lowe et al., 2001).

É importante salientar que os resultados obtidos nos estudos acima citados, tanto para a redução do $\mathrm{pH}$ urinário como para a redução da contagem bacteriana, podem apresentar variações decorrentes da dosagem administrada, do tempo de tratamento e da forma de administração do produto (suco, cápsulas, tabletes etc.), pois cada estudo apresentou um protocolo diferente.

A Escherichia coli foi a bactéria mais frequente $(90,62 \%)$ no isolamento bacteriano realizado das 32 amostras de urina positivas para cistite no dia 0 (antes do início do tratamento). Esses 
achados corroboram com diversos outros estudos que também encontraram a $E$. coli como a bactéria mais frequente em casos de ITU em porcas (Reis et al., 1992; Carr et al., 1995; Menin et al., 2008). Similarmente, em mulheres, a $E$. coli é o agente etiológico mais comum (Anderson et al., 2004; Meister, 2006; Mysorekar e Hultgren, 2006; Rosen et al., 2008). Portanto, se em seres humanos acredita-se que o oxicoco seja capaz de prevenir a ITU impedindo a $E$. coli de se aderir nas células uroepiteliais, o mesmo deve ocorrer em porcas.

Segundo Brito et al. (1999), a maioria das amostras de $E$. coli de origem suína, isoladas de infecções urinárias, apresentam diferentes perfis de plasmídios e resistência múltipla às drogas antimicrobianas. Essa resistência antimicrobiana demonstra a necessidade de novas alternativas para a prevenção e tratamento da ITU em porcas. O oxicoco poderia representar então uma importante solução em substituição a antibioticoterapia preventiva que vem sendo rotineiramente utilizada nas granjas. Estudo realizado por Howell et al. (2002) demonstraram que o consumo regular de suco de oxicoco evitou a adesão bacteriana nos casos de pacientes com ITU causadas por bactérias antibiótico-resistentes. Portanto, novos estudos devem ser realizados procurando avaliar a capacidade do oxicoco em prevenir ITU em porcas.

\section{CONCLUSÃO}

O produto comercial testado a base de oxicoco foi efetivo em promover a acidificação da urina, porém não foi observada qualquer outra ação, seja na análise do sedimento, na densidade urinária específica ou na contagem bacteriana.

\section{REFERÊNCIAS}

ANDERSON, G. G.; DODSON, K. W.; HOOTON, T. M. Intracellular Bacterial communities of urophatogenic Escherichia coli in urinary tract pathogenesis. Trends in Microbiology, v.12, n.9, p.424-430, 2004.

AVORN, J.; MONANE, M.; GURWITZ, J. H. et al. Reduction of bacteriuria and pyuria after ingestion of cranberry juice. The Journal of the American Medical Association, v.271, n.10, p.751-754, 1994.

BLATHERWICK, N. R. The specific role of foods in relation to the composition of urine. Archives of Internal Medicine, v.14, p.409-450, 1914.

BLATHERWICK, N. R.; LONG, M. L. Studies of urinary tract acidity. II. The increased acidity produced by eating prunes and cranberries. The Journal of Biological Chemistry, v.57, n.3, p.815-818, 1923.

BODEL, P. T.; COTRAN, R.; KASS, E. H. Cranberry juice and the antibacterial action of hippuric acid. Journal of Laboratory and Clinical Medicine, v.54, n.6, p.881-888, 1959.

BORUKH, I. F.; KIRBABA, V. I.; SENCHUK, G.V. Antimicrobial properties of cranberry. Voprosy Pitaniia Journal Articles, v.31, p.82, 1972.

BRIDGES, J. W.; FRENCH, M. R.; SMITH, R. L.; WILLIAMS, R. T. The fate of benzoic acid in various species. Biochemical Journal, v.116, n.1, p.47-51, 1970.

BRITO, B. G.; LEITE, D. S.; LINHARES, R. E. C.; VIDOTTO, M. C. Virulence factors of uropathogenic Escherichia coli strains isolated from pigs. Veterinary Microbiology, v.65, n.2, p.123-132, 1999.

CARR, J.; WALTON, J.; DONE, S. Cystitis and ascending pyelonephritis in the sow. In Practice, v.17, n.1, p.71-79, 1995.

ČESONIENĖ, L.; JASUTIENĖ, I.; ŠARKINAS, A. Phenolics and anthocyanins in berries of European cranberry and their antimicrobial activity. Medicina (Kaunas), v.45, n.12, p.992999, 2009.

DALLA COSTA, O. A.; SOBESTIANSKY, J. Como controlar a infecção urinária em matrizes suínas em produção. EMBRAPA Suínos e Aves: Instrução técnica para o suinocultor. Concórdia-SC, 1999.

DEE, S. A.; TRACY, J. D.; KING, V. Using citric acid to control urinary tract disease in swine. Veterinary Medicine, v.85, n.5, p.473-476, 1994. 
DER MARDEROSIAN, A. H. Cranberry juice. Drug Therapy, v.7, p.151-2, 1977.

DIGNAM, R.; AHMED, M.; DENMAN, S. The effect of cranberry juice on UTI rates in a long term care facility. Journal of the American Geriatrics Society, v.45, n.9, p.S553, 1997.

FAIRBROTHER, J.M., 2006. Urinary tract infection. In: STRAW, B.E.; ZIMMERMANN, J.J.; D' ALLAIRE, S.; TAYLOR, D.J. (Eds.). Diseases of Swine, 9 ed. Blackwell Publishing: Ames IA, USA, 2007, p.671-674.

FELLERS, C.R.; REDMON, B. C.; PARROTT, E. $M$. Effect of cranberries on urinary acidity and blood alkali reserve. The Journal of Nutrition, v.6, p.455-463, 1933.

FONTE, N. Tratamento da continência: Cuidado Urológico do Paciente com Lesão da Medula Espinhal. Journal of Wound Ostomy \& Continence Nursing, v.35, n.3, p.323-331, 2008.

HAVERKORN, M. J.; MANDIGERS, J. Reduction of bacteriuria and pyuria using cranberry juice. The Journal of the American Medical Association, v.271, n.10, p.751-754, 1994.

HOWELL, A. B.; FOXMAN, B. Cranberry juice and adhesion of antibioticresistant uropathogens. The Journal of the American Medical Association, v.287, n.23, p.3082-3083, 2002.

HOWELL, A. B.; REED, J. D.; KRUEGER, C. G. et al. A-type cranberry proanthocyanidins and uropathogenic bacterial anti-adhesion activity. Phytochemistry, v.66, n.18, p.2281-2291, 2005.

JACKSON, B.; HICKS, L. E. Effect of cranberry juice on urinary $\mathrm{pH}$ in older adults. Home Healthcare Nurse, v.15, p.198-202, 1997.

JONES, G. Cranberry extract against infertility. Pig Progress, v.19, n.10, 2003.

KAHN, H. D.; PANARIELLO, V. A.; SAELI, J. et al. Effect of cranberry juice on urine. Journal of the American Dietetic Association, v.51, p.251-254, 1967.

KIEL, R.; NASHELSKY, J. Does cranberry juice prevent or treat urinary tract infection? The Journal of Family Practice, v.52, p.154-155, 2003.

KINNEY, A.; BLOUNT, M. Effect of cranberry juice on urinary $\mathrm{pH}$. Nursing Research, v.28, p.287-290, 1979.

KIRCHHOFF, M.; RENNEBERG, J.; DAMKJAER, K. et al. Can ingestion of cranberry juice reduce the incidence of urinary tract infections in a department of geriatric medicine?
Ugeskrift for Laeger, v.163, p.2782-2786, 2001.

KOLLER, F.L.; BARCELLOS, D.;WENTZ, I.; BORTOLOZZO, F. Prevenção e Tratamento da Infecção Urinária em Matrizes Suínas. Porto Alegre, UFRGS. Setor De Suínos, 2006. Disponível em:

http://www.suinoculturaemfoco.com.br/fd/sa nidade11_2.php. Acessado em 02 de maio de 2010.

KONTIOKARI, T.; SUNDQVIST, K.; NUUTINEN, M.; POKKA, T. et al. Randomised trial of cranberry-lingonberry juice and Lactobacillus GG drink for the prevention of urinary tract infections in women. British Medical Journal, v.322, p.1571-1573, 2001.

LINSENMEYER, T. A.; HARRISON, B.; OAKLEY, A. et al.Evaluation of cranberry supplement for reduction of urinary tract infections in individuals with neurogenic bladders secondary to spinal cord injury. A prospective, double-blinded, placebo-controlled, crossover study. Journal of Spinal Cord Medicine, v.27, n.1, p.29-34, 2004.

LOWE, F. C.; FAGELMAN, E. Cranberry juice and urinary tract infections: what is the evidence? Urology, v.57, p.407-4013, 2001.

MENIN, A.; RECK, C.; CAPELLI, J. C.et al. Diagnóstico de infecção urinária em fêmeas suínas produtivas em granjas comerciais no sul do Brasil. Ciência Animal Brasileira, v.9, n.1, p.199-206, 2008.

MCLEOD, D. C.; NAHATA, M. C. Methenamine therapy and urine acidification with ascorbic acid cranberry juice. American Journal of Hospital Pharmacy, v.35, n.6, p.654, 1978.

MEISTER, A.R. Efeito do cloreto de amônio, ácido cítrico e cloreto de sódio no controle de cistites em porcas. 2006. Jaboticabal, $85 f$. Dissertação (Mestrado em Ciências Veterinárias) - Programa de Pós-graduação em Medicina Veterinária, Faculdade de Ciências Agrárias e Veterinárias-Unesp.

MOEN, D. V. Observations on the effectiveness of cranberry juice in urinary infections.

Wisconsin Medical Journal, v.61, p.282-283, 1962.

MYSOREKAR, I. U.; HULTGREN, SCOTT, J. Mechanisms of uropathogenic Escherichia coli persistence and eradication from the urinary tract. Proceedings of the National Academy of Sciences, v.103, n.38, p.14170-14175, 2006.

MROZ, Z. Organic acids as potential alternatives to antibiotic growth promoters for pigs.Advances in Pork Production, v.6, p.169-182, 2005. 
NATIONAL RESEARCH COUNCIL - NRC. Nutrient requirements of swine. 10. ed. Washington: National Academy Press, 1998.

OFEK, I.; GOLDHAR, J.; ZAFRIRI, D. et al. Anti-Escherichia coli adhesin activity of cranberry and blueberry juices. The New England Journal of Medicine, v.324, n.22, p.1599, 1991.

OLIVEIRA, F. H. Aspectos físico-químicos e microbiológicos da urina, $\mathrm{pH}$ e consistência das fezes de matrizes suínas suplementadas com ácido cítrico e cloreto de amônio. 2010. $73 f$. Dissertação (Mestrado em Ciência Animal) Programa de Pós-graduação em Ciência Animal, Escola de Veterinária da Universidade Federal de Goiás - UFG.

RAZ, R.; CHAZAN, B.; DAN, M. Cranberry Juice and Urinary Tract Infection. Clinical Infectious Diseases, v.38, p.1413-1419, 2004.

REID, G.; HSIEHL, J.; POTTER, P. et al. Cranberry juice consumption may reduce biofilms on uroepithelial cells: pilot study in spinal cord injured patients. Spinal Cord, v.39, n.1, p.26-30, 2001.

REIS, R. et al. Infecções urinárias em porcas. Arquivo Brasileiro de Medicina Veterinária, v.44, n.5, p.363-76, 1992.

ROSEN, D. A.; PINKNER, J. S.; JONES, J. M. et al. Utilization of an Intracellular Bacterial Community Pathway in Klebsiella pneumoniae Urinary Tract Infection and the Effects of FimK on Type 1 Pilus Expression. Infection and Immunity, v.76, n.7, p.3337-3345, 2008.

SANZ, M.; ROBERTS, J. D.; PERFUMO, C. J. et al. W. Assessment of sow mortality in a large herd. Journal of Swine Health and

Production, v.15, n.1, p.30-36, 2007.

SCHLAGER, T. A.; ANDERSON, S.; TRUDELL, J.; HENDLEY, J. O. Effect of cranberry juice on bacteriuria in children with neurogenic bladder receiving intermittent catheterization. The Journal of Pediatrics, v.135, n.6, p.698-702, 1999.

SCHMIDT, D.R.; SOBOTA, A.E. An examination of the anti-adherence activity of cranberry juice on urinary and nonurinary bacterial isolates.

Microbios, v.55, n.224-225, p.173-181, 1988.

SCHULTZ, A. Effect of cranberry juice and ascorbic acid in acidifying the urine in multiple sclerosis subjects. Journal of Community Health Nursing, v.1, p.159-169, 1984.

SOBESTIANSKY, J. Infecção urinária em fêmeas em produção. In: SOBESTIANSKY, J. e BARCELLOS, D. Doenças dos Suínos.

Goiânia : Cânone Editorial, 2007. p.127-141.
SOBOTA, A. E. Inhibition of bacterial adherence by cranberry juice: potential use for the treatment of urinary tract infections. Journal of Urology, v.131, n.5, p.1013-1016, 1984.

STOTHERS, L. A randomized trial to evaluate effectiveness and cost effectiveness of naturopathic cranberry products against urinary tract infection in women. The Canadian Journal of Urology, v.9, n.3, p.1558-1562, 2002.

STRASINGER, D. A. Uroanálise e Fluídos Biológicos. São Paulo: Editorial Premier Ltda, 1998.

WAITES, K. B.; CANUPP, K. C.; ARMSTRONG, S.; DEVIVO, M. J. Effect of cranberry extract on bacteriuria and pyuria in persons with neurogenic bladder secondary to spinal cord injury. Journal of Spinal Cord Medicine, v.27, n.1, p.35-40, 2004.

WALKER, E. B.; BARNEY, D. P.; MICKELSEN, J. N. et al. Cranberry concentrate: UTI prophylaxis. The Journal of Family Practice, v.45, n.2, p.167-168, 1997.

ZAFRIRI, D.; OFEK, I.; ADAR, R. et al. Inhibitory Activity of Cranberry Juice on Adherence of Type 1 and Type P Fimbriated Escherichia coli to Eucaryotic Cells. Antimicrobial agents and chemotherapy, v.33, n.1, p.92-98, 1989.

ZINSSER, H. H. Newer antibacterial drugs in urological infections. Medical Clinics of North America, v.48, p.293-304, 1964. 